\title{
Analysis of Functional Outcome in Proximal Humerus Plating (PHILOS) in Displaced Proximal Humerus Fracture
}

\section{Dhruv Pandya ${ }^{1}$ and Krunal Soni ${ }^{2 *}$}

${ }^{1}$ Senior Resident, Department of Orthopaedics, B. J. Medical College and Civil Hospital, Ahmedabad, Gujarat, India.

${ }^{2}$ Assistant Professor, Department of Orthopaedics, B. J. Medical College and Civil

Hospital, Ahmedabad, Gujarat, India

*Corresponding Author: Krunal Soni, Assistant Professor, Department of

Orthopaedics, B. J. Medical College and Civil Hospital, Ahmedabad, Gujarat, India.
Received: August 03, 2020

Published: October 20, 2020

(C) All rights are reserved by Dhruv Pandya and Krunal Soni.

\section{Abstract}

Background: Fractures of proximal humerus are common and debilitating injuries increasing seen in the elderly population [1]. Neer classification remains most widely used today [7]. Optimal treatment of three- or four-part fractures of proximal part of the humerus in elderly patients is controversial. However, recent advances in fracture fixation technology has led to development of fixed angle locked plates (PHILOS) that maintain angular stability under load [18].

Methods: This retrospective study included 41 patients aged > 18 years with fractures of the proximal humerus, including two-, three-, and four-part fractures, treated by open reduction and internal fixation with PHILOS plating. Patients were functionally evaluated based on subjective (35 points) and objective (65 points) parameters as per the Neer scoring system.

Results: All these operated patients were followed up for 12 - 18 months. Functional outcome based on the Neer scoring system showed 32 patients had good outcome scores (78\%) which include excellent and satisfactory result, whereas 9 patients had poor outcome scores (22\%) which include unsatisfactory and failure results, out of which 4 patients had avascular necrosis and were treated with Shoulder Hemiarthroplasty, 4 patients presented with varus malunion and treated with Osteotomy and revision plating and 1 patient underwent implant removal and physiotherapy.

Conclusion: Proximal humerus locking plate is a preferred option for management of in all types of Neer's fracture types of proximal humerus and fracture dislocation of proximal humerus. The present study concludes that it is a promising implant working by a dual mechanism i.e. a buttressing effect laterally and inferomedial support by locking screws, which prevent varus displacement of proximal fragment and thus it provides a good functional outcome in proximal humerus fractures.

However, complications are not uncommon with PHILOS plates. And therefore, a thorough understanding of fracture morphology using pre-operative planning with 3D CT scan, sound surgical techniques and proper plate positioning is necessary to achieve good functional outcomes.

Keywords: Proximal Humerus Fracture; Neer Classification; Locking Plates

\section{Abbreviation}

PHILOS: Proximal Humerus Inter Locking System

\section{Introduction}

Fractures of proximal humerus are common and debilitating injuries increasing seen in the elderly population $[1,2]$. The 
common age group of presentation is typically between 65 and 75 years of age with gender differences, with approximately $70 \%$ to $80 \%$ of fractures occur in woman [1]. An annual incidence is between 63 and 105 fractures per 1,00,000 population per year $[1,2]$. They account for $5 \%$ of all fractures, with only hip and distal end of radius fractures in elderly being more common [3]. 85\% of the proximal humeral fractures are undisplaced, minimally displaced and usually treated non operatively, generally resulting in satisfactory outcome [1,5]. The remaining are significantly displaced and more difficult to manage [5]. There are substantial difficulties in classifying these injuries reliably and evaluating their outcome. Codman recognized that the proximal humerus tends to fracture along its physeal lines of fusion into four principle fragments (two tuberosities, the humeral head and the shaft) [6]. Neer subsequently refined these definitions to produce the classification that remains most widely used today [7]. Each one of the four fragments are considered as unique parts only if they are separated by more than $1 \mathrm{~cm}$ or angulated by more than 45 degrees to one another $[6,7]$.

The functional outcome is satisfactory in the majority of patients with one-part fractures involving the surgical neck of humerus, one-part greater tuberosity fractures, impacted two-part surgical neck, varus two-part surgical neck, three and four part impacted valgus fractures treated nonoperatively $[9,10,11,13]$. Non operative treatment of displaced, unstable and multi fragment fractures and fracture-dislocations is more controversial [11]. Major controversy surrounds more complex three- and four-part fractures, which account for approximately $10 \%$ of proximal humeral fractures [1]. There is considerable variation in treatment, expectation and likely outcome for different patients, depending on their age and functional capabilities before their injury because elderly population tend to tolerate stiffness and restricted range of motion well due to their sedentary lifestyle in comparison with young and active individuals [19,20,23,33,39].

Most tuberosity fractures take place secondary to the displacement of the head fragment and their degree of spatial displacement is initially minimal, relative to their normal anatomic position [8,11]. With non-operative treatment, progressive displacement may occur because of the unopposed pull of the rotator cuff muscles [14]. Hence, non-operative treatment of these displaced fractures is more controversial [15]. Non-union, osteonecrosis and symptomatic malunion are major complications which may occur after nonoperative treatment [16]. Hence, in majority of cases operative treatment is mandatory for better outcome.

Optimal treatment of three- or four-part fractures of proximal part of the humerus in elderly patients is controversial with many advocating prosthetic replacement of humeral head [17]. Open reduction and internal fixation of these fractures with standard implants has been discouraged. However, recent advances in fracture fixation technology has led to development of fixed angle locked plates that maintain angular stability under load [18]. Biomechanical data suggest that these implants can resist physiological loads in osteoporotic bone and may provide an alternative to hemiarthroplasty. Clinical series have demonstrated some success with use of these plates for two-part fractures, but their clinical utility for three- and four-part fractures remain unclear [19].

There are advantages and disadvantages of both techniques used to treat three- and four-part fractures of proximal humerus. The advantages of open reduction and plate fixation are accuracy of articular reduction which help to improve functional outcome and greater stability of fixation using locking internal fixation plates $[18,19,20,24]$. The disadvantages include risk of osteonecrosis, mechanical impingement due to high placement of plate, malunion, implant failure, non-union [20]. Rotator cuff dysfunction from early tuberosity redisplacement or non-union is major reason for unsatisfactory functional outcome [21].

Absolute indications for an operative treatment of proximal humerus comprise three- or four- part fracture dislocations, headsplitting fractures, pathological fractures, open fractures, severe ipsilateral injuries to the shoulder girdle, and accompanying neurovascular injuries. However, in fractures with a displacement greater than $5 \mathrm{~mm}$, it is recommended for open reduction and internal fixation with locking plates for the greater accuracy and stability of reduction and also due to the poor outcome associated with secondary salvage surgery in patients treated non operatively $[23,24]$.

The goals in treating proximal humeral fractures are:

1. To restore the joint surface.

2. To restore the correct mechanical alignment.

3. To achieve optimal healing of the bone and ligaments.

4. To allow painless full range of motion of the shoulder joint. 
5. There is difficulty in maintaining brace and poor results of conservative management, with increasing sports activity and modern lifestyle, anatomical reduction and stable fixation with early rehabilitation is preferred.

\section{Aims and Objectives}

1. To assess the functional outcome of proximal humerus fractures managed with proximal humerus locking plate by evaluating with a scoring system.

2. Correlation of the functional outcome with radiological axis of the fixation with proximal humerus locked plates and its comparison between different types of fractures.

3. Correlation between degree of initial displacement or angulation of the fracture fragments with final functional outcome.

4. To note incidence of complications in patient managed proximal humerus locking plate in different type of fractures.

\section{Materials and Methods}

Institutional ethical approval was obtained, and this retrospective study included 41 cases of proximal humerus fractures treated surgically in a Tertiary care hospital attached to a medical college between July 2014 to July 2019 with Proximal Humerus Inter Locking System (PHILOS) plate.

\section{Inclusion criteria:}

1. All displaced proximal humerus fracture managed operatively with proximal humerus locking plate.

2. Age of patient $>18$ years.

\section{Exclusion criteria:}

1. Metastatic and pathological fractures.

2. Children ( 0 - 18 years).

3. Undisplaced fractures treated conservatively.

4. Open fracture.

5. Other fractures in ipsilateral limb.

6. Major nerve injury (e.g. axillary nerve or deltoid palsy).

\section{Methodology of study}

Fractures were classified as per Neer classification. Demographic data, date of injury, date of surgery, time interval between injury and surgery, surgical approach and fixation, wound complications before and after surgery were recorded. On follow- up patients were examined for local infection, range of motion and pain and functional assessment was done using Neer score. Radiographic assessment was done for alignment, fracture union, implant loosening, loss of reduction, evidence of avascular necrosis and it was corelated with functional outcomes, pain and shoulder range of motion. We assessed Neer score and graded patients accordingly.

NEER score [34]: Neer score is shoulder score by American Academy of Orthopedic Surgeons. This Scoring system combines assessment four parameters namely Pain, Function, Range of motion, and Anatomy. The maximum score is 100.

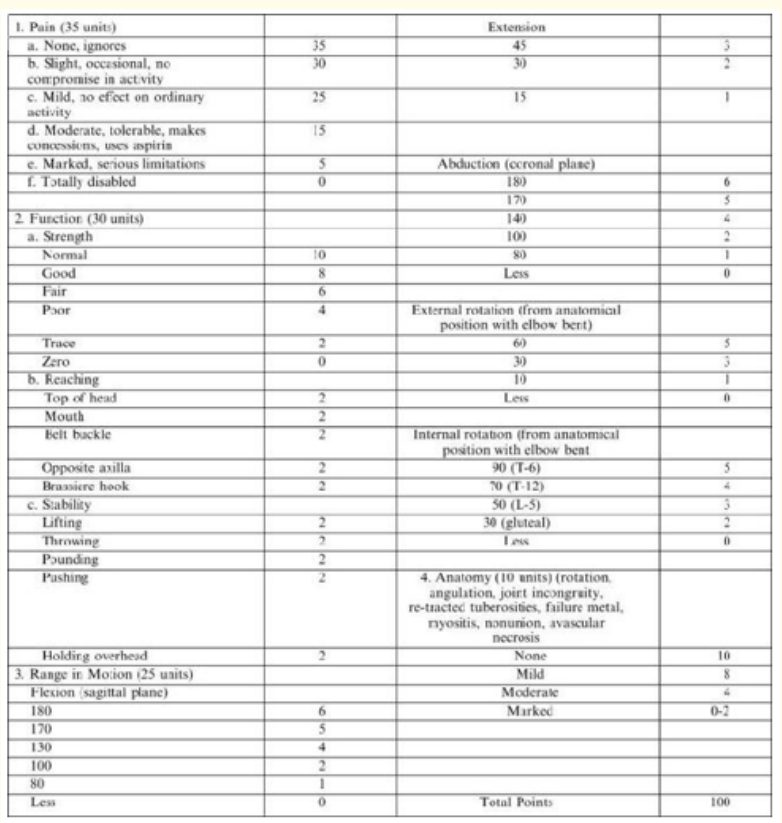

Figure

\section{Statistical analysis}

Descriptive analysis was used to present the collected data. Because of limited sample size and non- normal distribution of data, non-parametric statistical methods were employed. Results were collected and categorized with respect to Neer's criteria. We used standard $\mathrm{T}$ test to obtain the mean Neer score of all groups and used Chi-square test to obtain the power of significance ' $p$ ' value. All analysis was performed using STATA software.

\section{Results}

This study included 41 cases of proximal humerus fractures treated surgically with proximal humerus locking plates. 
The mean age of the patient was 53.7 years (ranging from 25 to 82 years) including 22 male and 19 female patients.

\begin{tabular}{|c|c|c|}
\hline Age Group & No of Patients & Percentage \\
\hline $21-30$ & 3 & 7.31 \\
\hline $31-40$ & 8 & 19.51 \\
\hline $41-50$ & 4 & 9.75 \\
\hline $51-60$ & 14 & 34.14 \\
\hline $61-70$ & 6 & 14.63 \\
\hline $71-80$ & 5 & 12.19 \\
\hline $81-90$ & 1 & 2.43 \\
\hline
\end{tabular}

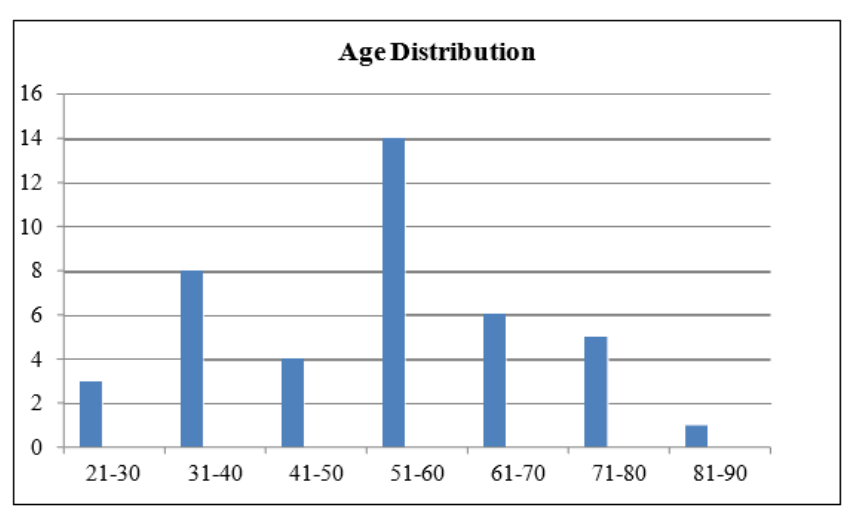

Table 1: Age distribution.

\begin{tabular}{|l|c|c|c|}
\hline Sex & No of Patients & Percentage & Mean Age \\
\hline Male & 22 & 53.65 & 51 \\
\hline Female & 19 & 46.34 & 56.8 \\
\hline
\end{tabular}

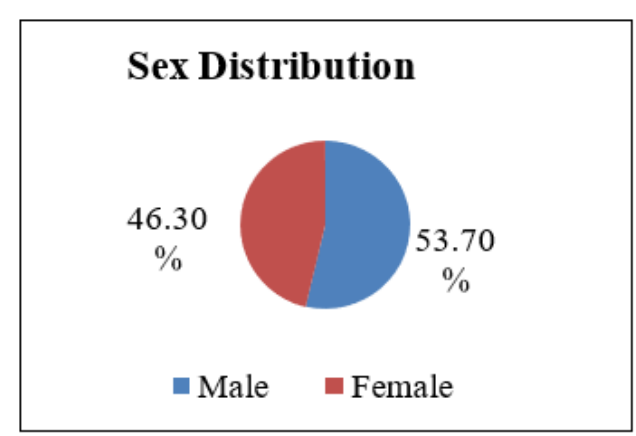

Table 2: Gender distribution.

There was no sex predominance and fractures had almost similar incidence with $53.7 \%$ in male, slightly more than female (46.3\%).

\begin{tabular}{|l|c|c|}
\hline Mode of Injury & No of Cases & Percentage \\
\hline RTA & 22 & 53.65 \\
\hline FALL & 19 & 46.34 \\
\hline
\end{tabular}

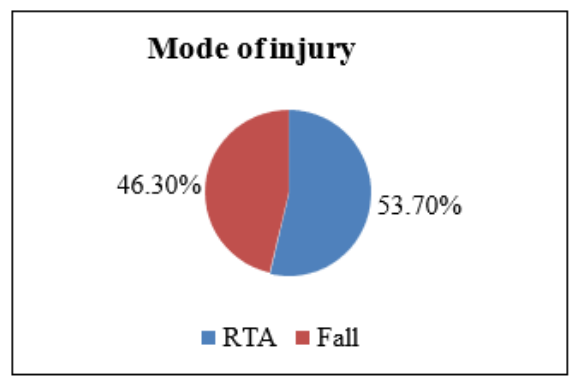

Table 3: Mode of injury.

Most common mode of injury being high energy two wheeler accident (53\%) and $46 \%$ patients had history of fall who were in the osteoporotic age group with poor bone quality.

\begin{tabular}{|l|c|c|}
\hline $\begin{array}{l}\text { Type of fracture by } \\
\text { Neer classification }\end{array}$ & No of cases & $\begin{array}{c}\text { Percentage of } \\
\text { distribution }\end{array}$ \\
\hline 2 Part & 18 & 43.9 \\
\hline 3 Part & 16 & 39.02 \\
\hline 4 Part & 04 & 9.75 \\
\hline Fracture Dislocation & 03 & 7.31 \\
\hline
\end{tabular}

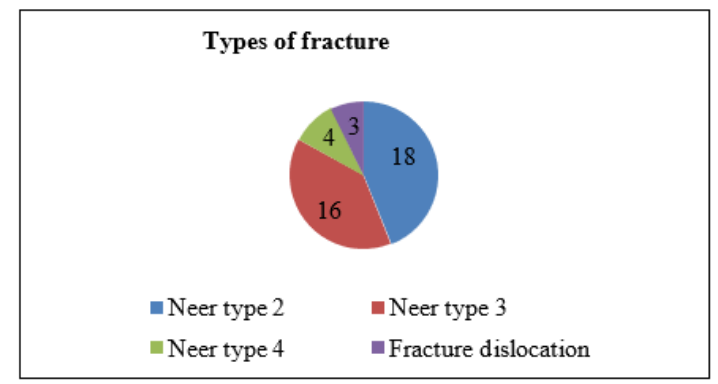

Table 4: Types of fracture according to NEER classification.

In our study out of total 41 patients, $43 \%$ were of Neer type 2 , $39 \%$ were of Neer type 3, only $9 \%$ were of Neer type 4 and $7 \%$ were of fracture dislocation. Two-part proximal humerus fracture was most common type in our study group.

In this study, out of 41 patients, 32 patients had good outcome scores $(78 \%)$ which include excellent and satisfactory result, whereas 9 patients had poor outcome scores (22\%) which include unsatisfactory and failure results, out of which 4 patients had avas- 
cular necrosis and were treated with Shoulder Hemiarthroplasty, 4 patients presented with varus malunion and treated with Osteotomy and revision plating and 1 patient underwent implant removal and physiotherapy.

\begin{tabular}{|l|c|c|c|c|c|}
\hline $\begin{array}{l}\text { Type of } \\
\text { Fracture }\end{array}$ & $\begin{array}{c}\text { No. of } \\
\text { Cases }\end{array}$ & $\begin{array}{c}\text { Excel- } \\
\text { lent }\end{array}$ & $\begin{array}{c}\text { Satis- } \\
\text { factory }\end{array}$ & $\begin{array}{c}\text { Unsatis- } \\
\text { factory }\end{array}$ & $\begin{array}{c}\text { Fail- } \\
\text { ure }\end{array}$ \\
\hline 2 part & 18 & 13 & 04 & 01 & -- \\
\hline 3 part & 16 & 08 & 04 & 02 & 01 \\
\hline 4 part & 04 & 01 & 01 & 02 & -- \\
\hline $\begin{array}{l}\text { Fracture } \\
\text { Disloca- } \\
\text { tion }\end{array}$ & 03 & 01 & -- & -- & 02 \\
\hline
\end{tabular}

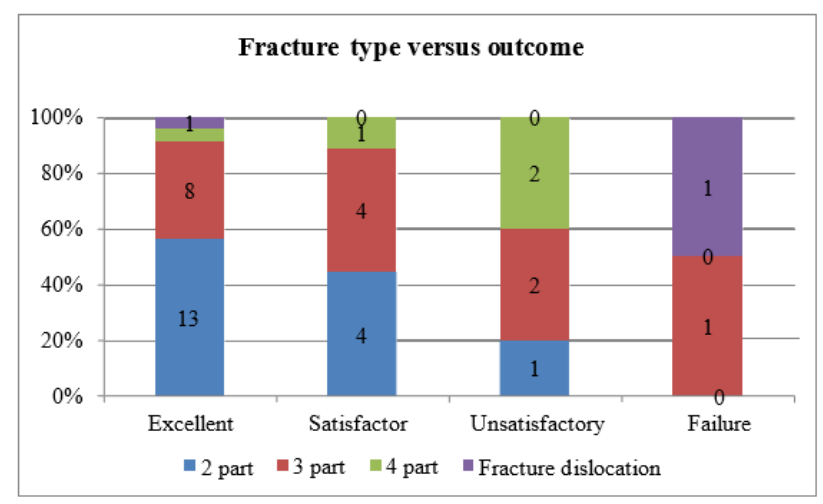

Table 5: Functional assessment score.

\begin{tabular}{|l|c|c|c|}
\hline Result & Score & No of cases & Percentage \\
\hline Excellent & $>89$ & 22 & 53.65 \\
\hline Satisfactory & $80-89$ & 10 & 24.39 \\
\hline Unsatisfactory & $70-79$ & 05 & 12.19 \\
\hline Failure & $<70$ & 04 & 09.75 \\
\hline
\end{tabular}

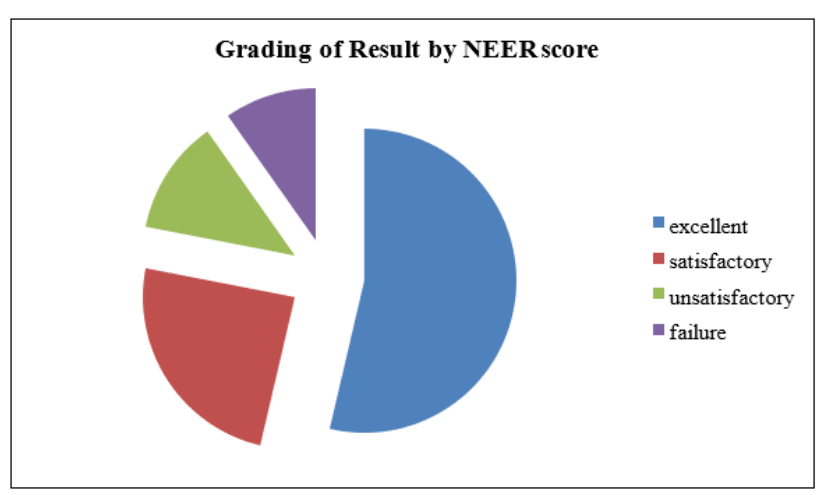

Table 6: Grading of results by Neer's score.

\begin{tabular}{|l|c|c|}
\hline Neer's classification & No. of subjects & Mean Neer score \\
\hline 2 part \# & 18 & 94.5 \\
\hline 3 part \# & 16 & 84.3 \\
\hline 4 part \# & 4 & 84 \\
\hline \# dislocation & 3 & 60.6 \\
\hline
\end{tabular}

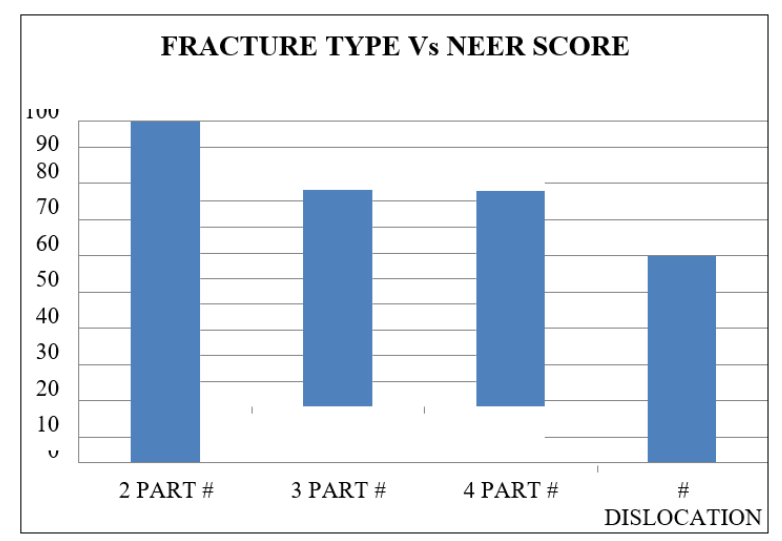

Table 7: Mean Neer score vs Neer's classification type.

As per the above table comparing of Neer score between different Neer's classification group, the results can be summarized as below.

There is statistically significant difference between all four groups with respect to Neer score. Neer score of type 2 fracture is better than type 3 and type 4 fracture ( $p$ value $<0.05$ ) and this can be justified by the fact that Neer Type 2 fractures are associated with less communication, better surgical fixation and good final outcome in comparison with Neer Type 3 and 4.

\begin{tabular}{|l|c|c|}
\hline Age groups (in years) & $\begin{array}{c}\text { No. of } \\
\text { subjects }\end{array}$ & $\begin{array}{c}\text { Mean Neer } \\
\text { score }\end{array}$ \\
\hline $20-39$ & 8 & 97.2 \\
\hline $40-59$ & 19 & 83.7 \\
\hline 60 and above & 14 & 79.1 \\
\hline
\end{tabular}

Table 8: Mean Neer score vs age groups.

Mean Neer score was calculated in different age groups which summarized as - Mean Neer score in younger age group was better (Mean score of 97.2 in age group 20 - 39 year and Mean score of 83.7 in age group of 40 - 59 years) than it is in old and very old age groups (Mean score of 79.1 in age of 60 years and above) ( $p$ value $<0.05$ ). 


\begin{tabular}{|l|c|c|}
\hline Complication & No of cases & Percentage \\
\hline Shoulder stiffness & 04 & 9.75 \\
\hline Screw penetration into joint & 03 & 7.31 \\
\hline Infection & -- & -- \\
\hline Nonunion & -- & -- \\
\hline Malunion & 04 & 9.75 \\
\hline Avascular necrosis & 04 & 9.75 \\
\hline High placement of plate & -- & -- \\
\hline Implant loosening & 01 & 2.43 \\
\hline No complication & 25 & 60.9 \\
\hline
\end{tabular}

Table 9: Post-operative complications.

In our study, out of 41 subjects, 4 patients had developed shoulder stiffness which gradually improved with physiotherapy, 3 patients had screw perforation and were advised implant removal and the final outcome was excellent, 4 patients had developed varus malunion, 4 patients had developed avascular necrosis and 1 patient developed loosening of implants immediate after surgery. 25 patients did not suffer from any significant complications $(61 \%$ of total cases).

\section{Discussion}

Fractures of proximal humerus poses a great challenge for orthopedic surgeon to achieve a balance between restoring the joint surface and minimizing complications. The proximal humerus locking plate aids in achieving accuracy of articular reduction which improves functional outcome and confers greater stability of fixation for early mobilization.

We assessed 41 patients with proximal humerus fracture managed with proximal humerus locking plate. The mean age of the study was 53.7 years (ranging from 25 to 82 years) with majority of patients in the age group of 41 - 59 years (46\%), which was consistent with the age incidence in studies done by Kenneth A. Egol., et al. [44] (61 years).

Study of literature reveals predominance of proximal humerus fractures in females of elderly age group [41]. Studies also reveal that male to female ratio being 1:0.8. In our study, there were 22 $(53.7 \%)$ male and $19(46.3 \%)$ female patients so ratio is $1: 0.8$. The fractures of proximal humerus have bimodal presentation with adolescents and younger middle age men who are more prone for high velocity injuries forming one group and later these fractures are seen in elderly patients ( $>50$ years) in which cases they are osteoporosis related and most often seen in females.
Of 41 cases, the number of women were 19 out of which majority (11 women) had history of domestic fall and the number of men were 22 out of which majority ( 14 men) had history of high velocity injury. These findings are similar with existing literature of Dolfi Herscvici., et al. which revealed $47.5 \%$ road traffic accidents, 50\% history of fall and $2.5 \%$ history of assault out of 40 cases studied [45]. The most common mode of injury in young is RTA and in elderly it is Domestic Fall, which is consistent with world literature.

The fracture of all 41 patients were classified using Neer's classification. There were 18 patients (44\%) of Neer type 2 fracture, 16 patients (39\%) of type 3 fractures, 4 patients $(10 \%)$ of type 4 fractures and 3 patients (7\%) of fracture dislocation. Neer type 2 fracture was most common type in study group. Incidence of type of fracture is nearly consistent with the studies in literature.

\begin{tabular}{|l|c|c|c|c|}
\hline Study & $\begin{array}{c}\text { 2 Part } \\
\#\end{array}$ & 3 Part \# & $\begin{array}{c}\text { 4 Part } \\
\#\end{array}$ & $\begin{array}{c}\text { \# Dislo- } \\
\text { cation }\end{array}$ \\
\hline $\begin{array}{l}\text { Rizwan Shahid., } \\
\text { et al. }\end{array}$ & $\begin{array}{c}11 \\
(22 \%)\end{array}$ & $\begin{array}{c}21 \\
(42 \%)\end{array}$ & $\begin{array}{c}18 \\
(36 \%)\end{array}$ & 00 \\
\hline Ma Fazal., et al. & $\begin{array}{c}13 \\
(48 \%)\end{array}$ & $\begin{array}{c}12 \\
(45.5 \%)\end{array}$ & $\begin{array}{c}02 \\
(7.5 \%)\end{array}$ & 00 \\
\hline Our Study & $\begin{array}{c}18 \\
(44 \%)\end{array}$ & $\begin{array}{c}16 \\
(39 \%)\end{array}$ & $\begin{array}{c}04 \\
(9 \%)\end{array}$ & $03(7 \%)$ \\
\hline
\end{tabular}

Table 10: Neer classification types in various studies.

As per the fracture morphology, fracture fragment displacement and surgeon choice, 36 patients were operated through deltopectoral approach and 5 were through deltoid splitting approach. There was no neurological deficit due surgical or anaesthetic complications.

Out of the 41 patients followed up, 22 patients had excellent scores, 10 had satisfactory scores, 5 had unsatisfactory scores and 4 had poor outcome scores. Excellent score indicates anatomical and stable fixation of articular surface.

Mean Neer score was 87 for all fracture types (range 29 - 100 points). Mean Neer score for two- part fracture was 94.5 , for threepart fracture was 84.3 , for four-part fracture was 84 and for fracture dislocation mean Neer score was 60. There was no significant difference in outcome of type 3 and type 4 fractures Neer scores. Mean Neer score for middle age group (20 - 39) was 97, for old age group (40 - 59) was 84 and for very old age group (>60) was 79. As indicated from the date mentioned, the Mean Neer score was less in old age group in comparison with younger patients and therefore it suggests that there are more chances of loss of reduction in elderly due to osteoporosis as compared to young age group $[39,41]$. 
Total active motion was calculated by sum of all movements, comparing it with normal limb range of motion. In our study mean of total active motion was $83.3 \%$.

The treatment of complex humeral 3- or 4-part fractures represents a challenge. The surgeon must obtain an exact anatomical reduction and stable fixation, and at the same time minimize the iatrogenic risk of screw penetration and avascular necrosis of humeral head by maximal protection of the periarticular soft tissues.

Poor results in these complex fractures are due to following causes:

1. Inadequate fracture reduction especially medial cortex.

2. Unstable fixation.

3. Incorrect positioning of the fixation devices.
Functional scores achieved with different treatment options for proximal humeral fractures in the current literature.

The common complications after fixation of fractures of proximal humerus are shoulder stiffness and restricted movements, wound infection, failure of fixation, avascular necrosis of humeral head and late rupture of the rotator cuff.38,39 In our study, 4 patients had shoulder stiffness, 4 patients had varus collapse and malunion, 4 patients had aseptic necrosis of humeral head, 3 patients had screw penetration in to the shoulder joint and 1 patient had implant loosening.

4 patients suffered from shoulder stiffness, three of which were elderly. Stiffness is more of surgical complication than implant and most of the patients improved with physiotherapy. 3 patients suffered from screw perforation and were advised for implant removal and on final follow up there is no significant poorer result in perforation of screws in joint.

\begin{tabular}{|l|c|c|c|}
\hline Study & Type of fixation & Neer score & Neer's classification \\
\hline Kuchle., et al. (2006) & Cloverleaf plate & 72.4 & 2- ,3- and 4-part fracture \\
\hline Ketter., et al. (2006) & Angle stable humerus plate & 70.0 & 2- , 3- and 4-part fracture \\
\hline Lill., et al. (2003) & Angle stable humerus plate & 72.5 & 2-, 3- and 4-part fracture \\
\hline Kollig., et al. (2003) & T plate, screws and k wires & 72.1 & 3- and 4-part fracture \\
\hline Wijgman., et al. (2002) & Classic T Plate cerclage & 80.0 & 3- and 4-part fracture \\
\hline Gerber et al & Internal fixation & 78 & 2- , 3-, and 4-part Fracture \\
\hline Hessman et al & T plate & 69 & 2-, 3-, and 4-part Fracture \\
\hline Our study & Locking plate & 87 & 2- ,3-, and 4-part Fracture \\
\hline
\end{tabular}

Table 11: Corelation of Neer score and Neer fracture type in various studies.

4 patients had developed varus collapse and malunion and were advised osteotomy and revision plating.

4 patients had developed osteonecrosis of the humeral head, out of which 2 patients had Neer's 4-part fracture and 2 patients had Neer's 4-part fracture dislocation. Avascular necrosis is not in itself a clinical problem. However, it may end up in partial or total collapse of the humeral head with incongruency. This may result in malfunction and pain. The development of aseptic humerus head necrosis ( 4 patients or $10 \%$ ) significantly affected the clinical result; these patients only achieved a mean Neer score of 46.5 .

\begin{tabular}{|l|c|c|c|}
\hline $\begin{array}{l}\text { Fracture of } \\
\text { Study }\end{array}$ & $\begin{array}{c}\text { Type of } \\
\text { Fracture }\end{array}$ & $\begin{array}{c}\text { Method of } \\
\text { Fixation }\end{array}$ & $\begin{array}{c}\text { Inci- } \\
\text { dence }\end{array}$ \\
\hline Hessmann., et al. & $\begin{array}{c}2,3 \text { and } 4 \\
\text { parts }\end{array}$ & T plate & $4 \%$ \\
\hline Fankhauser., et al. & AO - A, B, C & Locking plate & $10 \%$ \\
\hline Gerber., et al. & $\begin{array}{c}2,3 \text { and } 4 \\
\text { parts }\end{array}$ & Locking plate & $12 \%$ \\
\hline Our study & $\begin{array}{c}2,3 \text { and } 4 \\
\text { parts }\end{array}$ & Locking plate & $10 \%$ \\
\hline
\end{tabular}

Table 12: Aseptic necrosis rate in various studies. 
As shown in the table 12, the current literature depicts the rate of necrosis for 3-and 4-part fractures between $0 \%$ and $50 \%$, depending on the osteosynthesis procedure $[44,45]$. The rate of aseptic necrosis $(10 \%)$ in our study is acceptable and in accordance with the available literature. Since in the very old age group with osteoporosis, functional outcome after conventional plate osteosynthesis was poor $[49,51]$ and therefore in order to obtain better and reproducible results, the AO/ASIF has developed a special locking compression plate (PHILOS) for fractures of the proximal humerus [5].

In this study, most of the patients (i.e. 19 out of 41 ) were in the group of 40 - 59 years, a group highly prone for osteoporosis. Backing out of screws is a common feature when conventional plates are used for fixation in osteoporotic bones because it is difficult to hold the bony fragments as they are highly fragile due to osteoporosis. This accounts for the high rate of failure in procedures using conventional plates in an osteoporotic bone. However, with advent of locking plates, due to the locking of screws in the plate chances of cutting out of screws is significantly reduced. Also, due to multidirectional nature of screws in the locking plate, which spans through sphericity of head and not the center alone, this reduces the failure in fixation and collapse of head of humerus.

In our study final functional outcome is assessed with Neer's score. Out of the 41 patients followed up, 25 (60\%) patients had excellent scores with no effects on activities of daily living, 7 (17\%) had satisfactory scores with very little effect on activities of daily living, $5(12 \%)$ had unsatisfactory scores and $4(10 \%)$ had poor outcome scores and these patients had significant restriction and modification in activities of daily living, moderate pain and regular intake of analgesics and restricted Range of motion with weaker muscle strength.

These results are consistent with other studies too as mentioned in the table 13 below.

\begin{tabular}{|l|c|c|c|c|}
\hline Study & $\begin{array}{c}\text { Excel- } \\
\text { lent }\end{array}$ & $\begin{array}{c}\text { Satis- } \\
\text { factory }\end{array}$ & $\begin{array}{c}\text { Unsatis- } \\
\text { factory }\end{array}$ & Failure \\
\hline $\begin{array}{l}\text { AA Martinez., } \\
\text { et al. }\end{array}$ & $\begin{array}{c}13 \\
(22.4 \%)\end{array}$ & $\begin{array}{c}36 \\
(62 \%)\end{array}$ & $\begin{array}{c}08 \\
(13.8 \%)\end{array}$ & $\begin{array}{c}01 \\
(1.7 \%)\end{array}$ \\
\hline Richard J & 08 & 06 & 00 & $\begin{array}{c}01 \\
\text { Hawkins }\end{array}$ \\
\hline $53.3 \%)$ & $(40 \%)$ & $0.7 \%)$ \\
\hline Our Study & $\begin{array}{c}22 \\
(54 \%)\end{array}$ & $\begin{array}{c}10 \\
(24 \%)\end{array}$ & $\begin{array}{c}05 \\
(12 \%)\end{array}$ & $\begin{array}{c}04 \\
(10 \%)\end{array}$ \\
\hline
\end{tabular}

Table 13: Outcome in various studies.

\section{Conclusion}

Management of fractures of proximal humerus is still a challenging and controversial task due to different personalities of fractures and variable bone quality, especially in elderly population.

Proximal humerus locking plate is a preferred option for management of in all types of Neer's fracture types of proximal humerus and fracture dislocation of proximal humerus. Proximal Humeral Internal Locking system (PHILOS) provides an angle stable construct with a combination of both divergent and convergent screw orientation and hence decreasing pull out of screws and decreasing chances of failure of fixation. The present study concludes that it is a promising implant working by a dual mechanism i.e. a buttressing effect laterally and inferomedial support by locking screws, which prevent varus displacement of proximal fragment and thus it provides a good functional outcome in proximal humerus fractures.

In the present study of 41 patients treated with PHILOS plating, 22 patients had excellent scores, 10 had satisfactory scores, 5 had unsatisfactory scores and 4 had poor outcome scores. Therefore, based on these findings $\mathrm{m}$ is can be concluded that the overall functional outcomes of PHILOS plates are good especially in elderly patient with compromised bone quality and in comminuted fractures.

In our present study we measured the three radiographic indicators on follow-up which are associated with poor functional outcome; varus angulation with NSA less than $120^{\circ}$, superior displacement of greater tuberosity and medial gap of more than 4 $\mathrm{mm}$ [46]. PHILOS plating helps to minimize the chances of these three complications by providing a angular stable construct and thus improving the functional outcomes.

However, complications are not uncommon with PHILOS plates. As in our study we demonstrated a poor outcome in $9(21 \%)$ out of 41 patients. This can be attributed to complex fracture pattern, improper surgical technique and inadequate positioning of the implant. And therefore, a thorough understanding of fracture morphology using pre-operative planning with 3D CT scan, sound surgical techniques and proper plate positioning is necessary to achieve good functional outcomes.

\section{Limitations of the Study}

The study has several limitations. We are aware that study population is small and does not adequately represent all types of proximal humerus fracture, especially type 3 and type 4 fractures. All 4 types of fractures were not accounted in the equal number in the study. Long term follow-up would be desirable to effectively know the outcomes and a larger study is necessary with comparable fracture patterns in two groups to draw strong conclusions. 


\section{Clinical Case Examples}

Case No. 1: 25 years female patient with history of RTA while going in a 4-wheeler sustained Neer type 2 surgical neck proximal humerus fracture of left side.

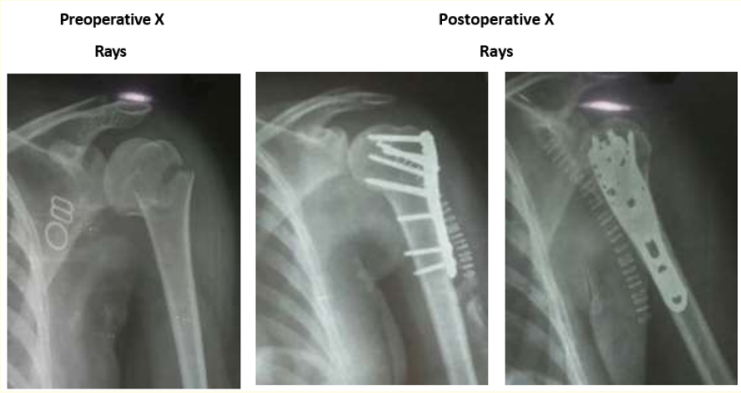

Final Follow-up X-rays
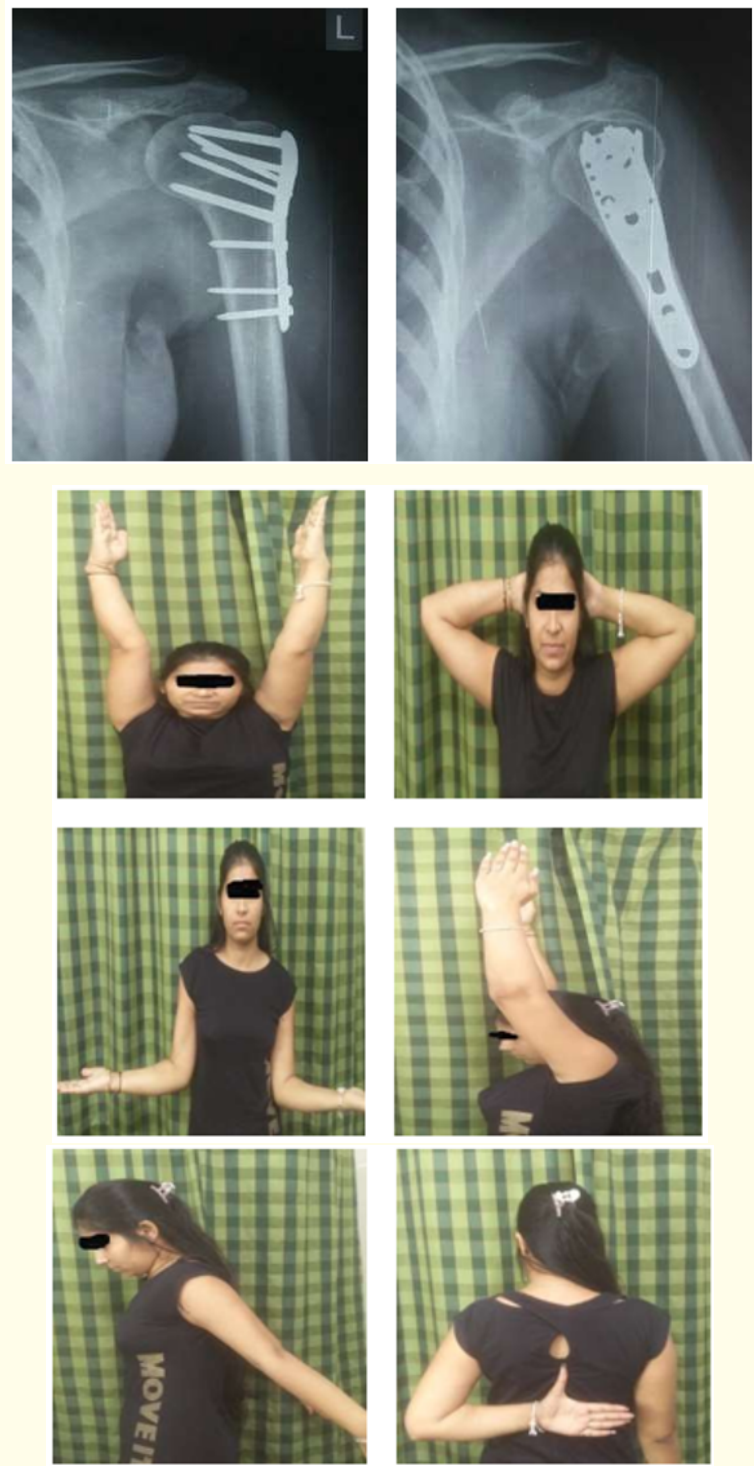

Case No. 2: 60 years old male with history of domestic fall down sustaining Neer type 3 proximal humerus fracture over left side.
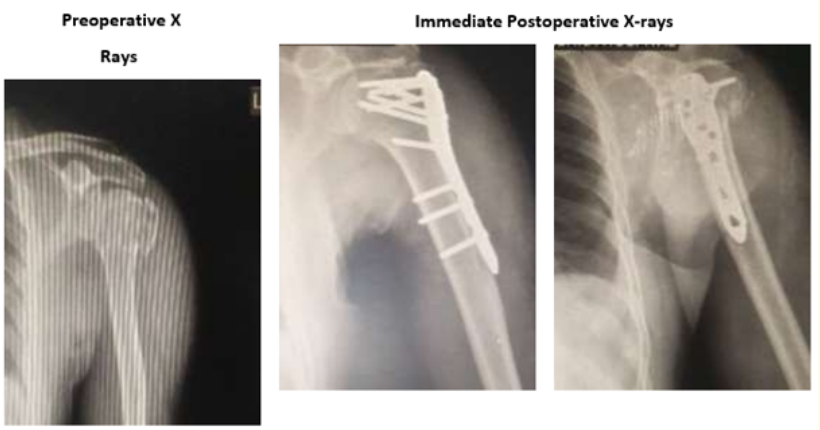

Final Follow-up X-rays
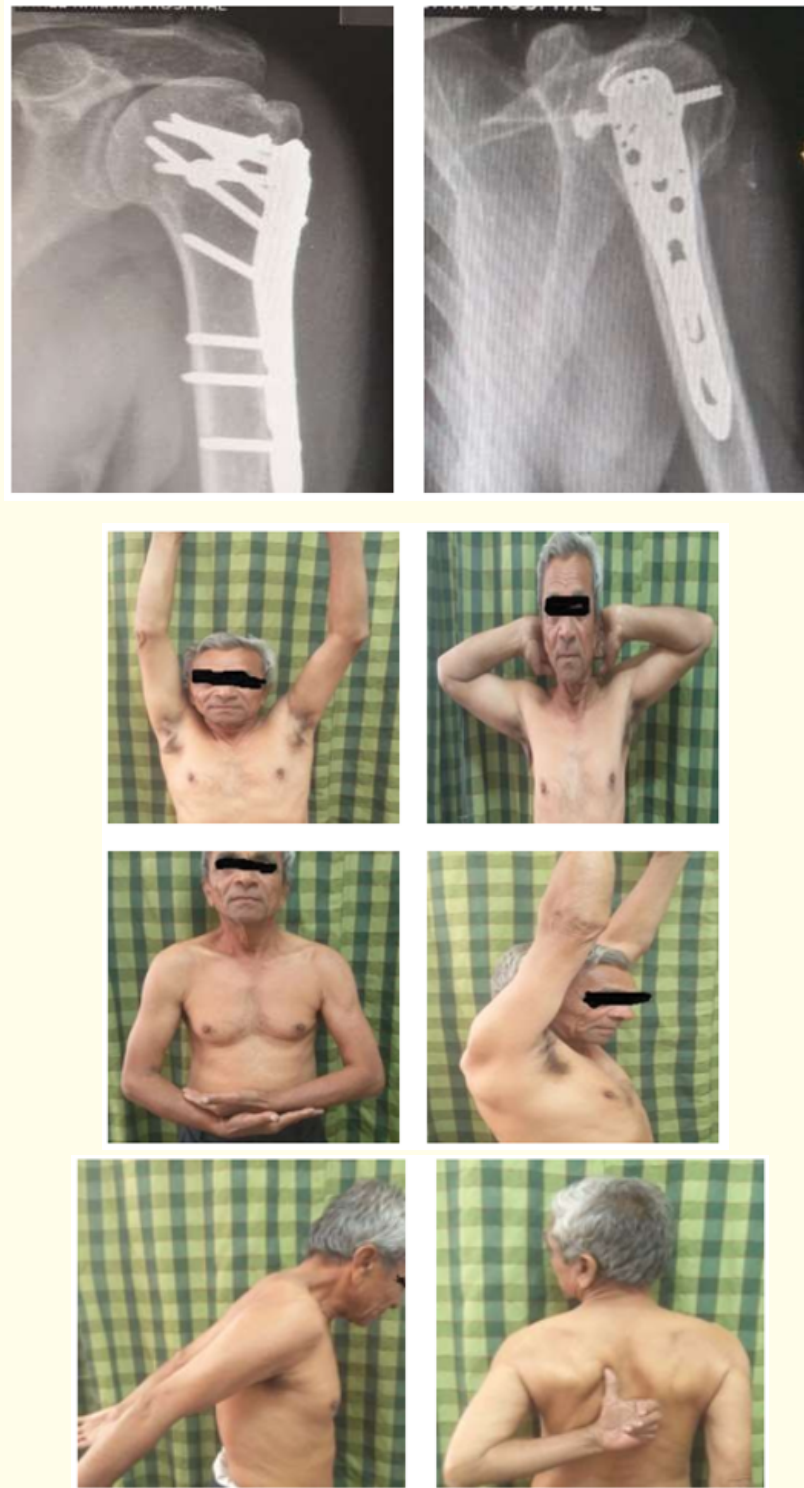

Figure 2

Figure 1 
Case no. 3: 36 years old male with history of RTA while driving a 4-wheeler sustained Neer 4 part proximal humerus fracture with split head of humerus of left side.
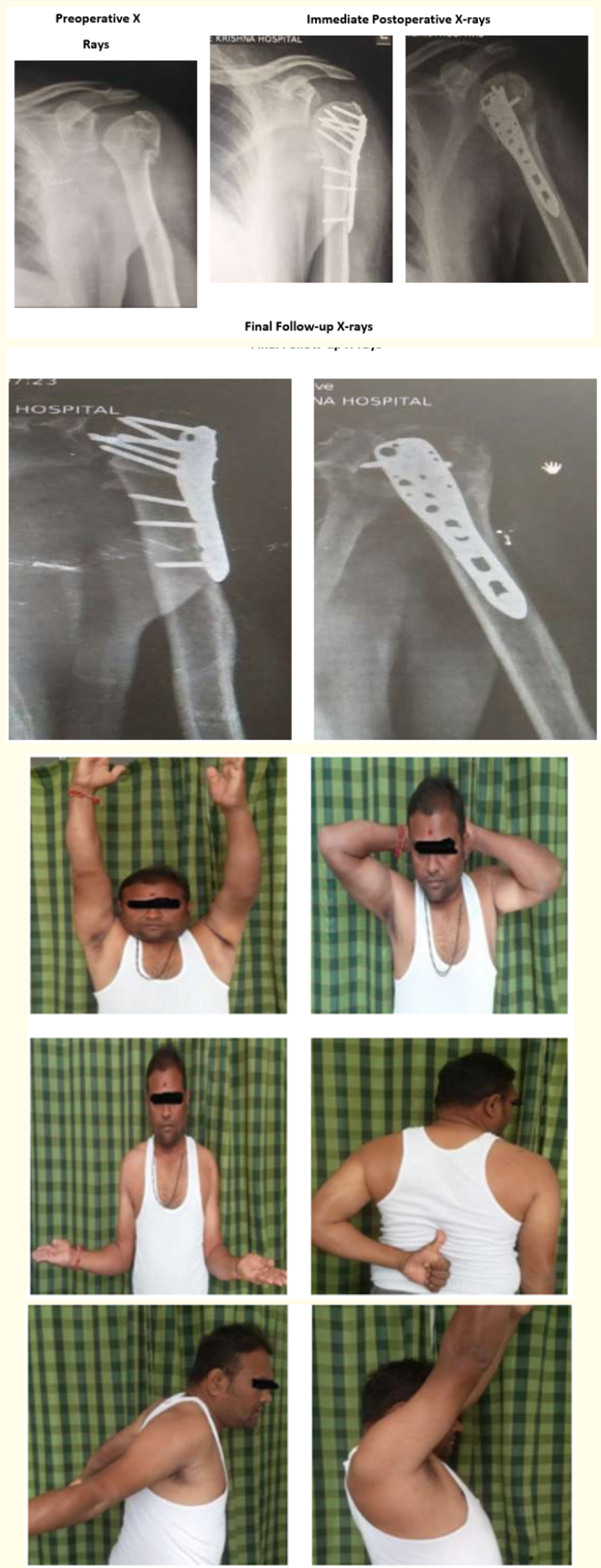

Figure 3
Case no. 4: 68 years old male with history of RTA while riding a bike sustained Neer 2 part fracture dislocation of proximal humerus of right side.
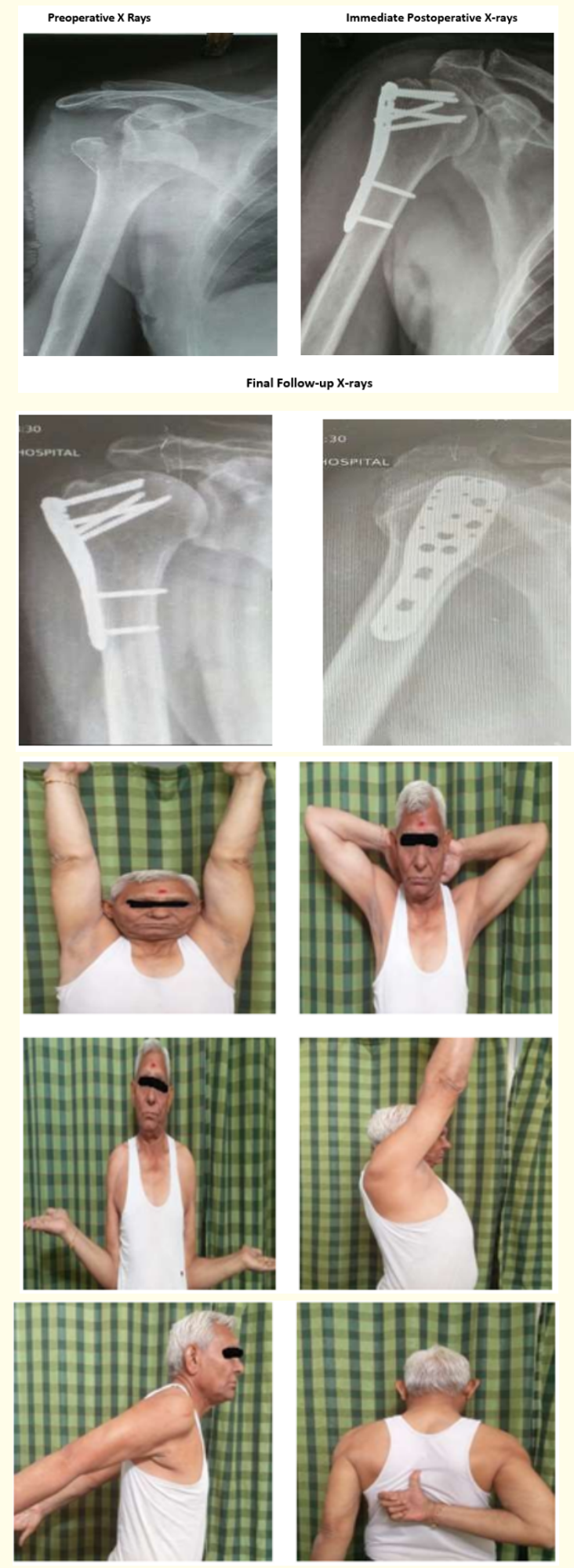

Figure 4 
Case no. 5: 55 years old male with history of RTA while riding a bike sustained Neer 3 part fracture dislocation of proximal humerus of right side.
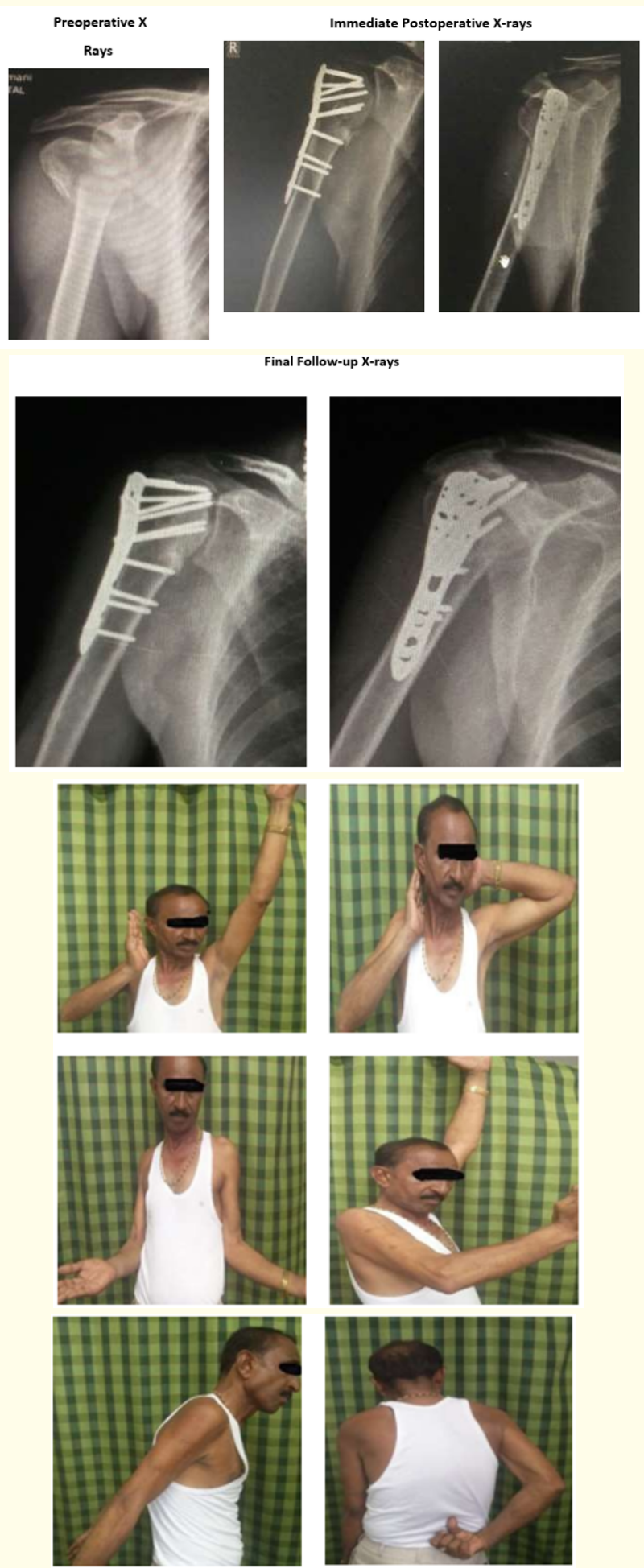

Figure 5

\section{Conflict of Interest}

No conflict of interest.

\section{Bibliography}

1. Court Brown CM., et al. "The epidemiology of proximal humeral fractures". Acta Orthopaedica Scandinavica 72 (2001): 365-371.

2. Palvanen M., et al. "The epidemiologpy of proximal humeral fractures". Clinical Orthopaedics and Related Research 442 (2006): 87-92.

3. Young TB and Wallace WA. "Conservative treatment of fractures and fracture - dislocation of the upper end of the humerus". The Journal of Bone and Joint Surgery British 67B (1985): 373-377.

4. Codman EA. "The Shoulder. Rupture of the supraspinatus tendon and other lesions in or about the subacromial bursa". Boston: privately printed (1934).

5. Neer CS. "Four segment classification of proximal humeral fractures: purpose and reliable use". Journal of Shoulder and Elbow Surgery 11 (2002): 389-400.

6. Clifford PC. "Fractures of neck of humerus: a review of the late results". Injury 12 (1980): 91-95.

7. Platzer P., et al. "The influence of displacement on shoulder function in patients with minimally displaced fractures of the greater tuberosity". Injury 36 (2005): 1185-1189.

8. Court Brown CM., et al. "The translated two part fracture of the proximal humerus Epidemiology and outcome in order patient". The Journal of Bone and Joint Surgery British 83 (2001): 799-804.

9. Court Brown CM., et al. "Impacted valgus fractures B1.1 of the proximal humerus. The results of non operative treatment". The Journal of Bone and Joint Surgery British 84B (2002): 504508.

10. Edelson G., et al. "Natural history of complex fractures of the proximal humerus using a three dimensional classification system". Journal of Shoulder and Elbow Surgery (2008): 399409.

11. Green A., et al. "Humeral head replacement for acute four part proximal humeral fractures". Journal of Shoulder and Elbow Surgery 2 (1993): 249-254.

12. Walsh S., et al. "Biomechanical comparison of unique locking plate versus a standard plate for internal fixation of proximal humerus fractures in a cadaveric model". Clinical Biomechanics 21 (2006): 1027-1031. 
13. Brian D Solberg and Moon CN Franco DP. "Surgical treatment of three and four part proximal humeral fractures". Journal of Bone and Joint Surgery American (2009): 1689-1697.

14. Rockwood and Green's Fractures in Adults, $7^{\text {th }}$ edition, volume 1. Proximal humerus fractures 1066.

15. Murray IR., et al. "Proximal humeral fractures: current concepts in classification, treatment and outcomes". The Journal of Bone and Joint Surgery British 93 (2011): 1-11.

16. "Displaced proximal humeral fractures". Journal of Bone and Joint Surgery 52.6 (6): 1077-1089.

17. P Hoffmeyer. "The operative management of displaced fractures of the proximal humerus". Journal of Bone and Joint Surgery (2002): 84.4 (2002): 469-480.

18. Lill H., et al. "The angle stable locking-proximal-humerus plate for proximal humeral Fractures using a small anterior-lateral deltoid-splitting-approach". Zentralblatt fur Chirurgie 129.1 (2004): 43-48.

19. Hertel R., et al. "Predictors of humeral head ischemia after intracapsular fracture of the proximal humerus". Journal of Shoulder and Elbow Surgery 13 (2004): 427-433.

20. Functional outcome and complications following PHILOS plate fixation in proximal humeral fractures.

21. Lei Zhang., et al. "The clinical benefit of medial support screws in locking plating of proximal humerus fractures: a prospective randomized study". International Orthopaedics 35 (2011): 1655-1661.

22. Second generation locked plating for complex proximal humerus fractures in very elderly patients.

23. Brian D Solberg., et al. "Surgical treatment of three And fourpart proximal humeral fractures". The Journal of Bone and Joint Surgery 91 (2009): 7.

24. Rockwood and Matsen. "The Shoulder". W.B. Saunders company (1993): 337-379.

25. Samuel L Turek. "Orthopaedics- Principles and their applications" $4^{\text {th }}$ edition 2 (): 920-922.

26. Kenneth J Koval Maureen. "Functional outcome after minimal displaced fracture of proximal Humerus". Journal of Bone and Joint Surgery 72.2 (1997): 203-208.

27. Hattrup SJ and Cofield RH. "Osteonecrosis of humeral head - Results of replacement". Journal of Shoulder and Elbow Surgery 9 (2000): 177.
28. Jeffrey AS and David MD. "Proximal fractures malunions". OCNA (2000).

29. Kozlowski P. "Subcut Osteosynthesis for non-union of humeral shaft fractures". Journal of Bone and Joint Surgery (1997): 79.

30. Campbell JT. "Periprosthetic humeral fractures - Mechanism of fracture and treatment options". Journal of Shoulder and Elbow Surgery 7 (1998): 406.

31. Partick G., et al. "Fracture of an implant after total shoulder arthroplasty". Journal of Shoulder and Elbow Surgery 79 (1997): 4.

32. Crosby LA. "Complications, Total Shoulder arthroplasty, Rosemont 1ll, 2000". American Academy of Orthopaedic Surgeons (2000).

33. Sperling JW and Cofield RH. "Infection after total shoulder arthroplasty”. Clinical Orthopaedics 382 (2001): 206.

34. Fabis J. "Boguckia-shoulder cuff Ruptures". Journal of Bone and Joint Surgery (1997): 79B.

35. Zwierzchowski $\mathrm{H}$ and Fabis J. "Cuff tear-Primary and Secondary Bone Impingement". Journal of Bone and Joint Surgery (1997): 79.

36. Richard J Hawkins., et al. "The three part fractures of proximal part of humerus". Journal of Bone and Joint Surgery 68-A (1986): 1410-1414.

37. M Pritsch and A Greental. "Closed pinning for proximal humerus fractures". Journal of Bone and Joint Surgery (1997):79B.

38. Gerber C., et al. "Internal fixation of complex fractures of the proximal humerus". Journal of Bone and Joint Surgery 86.60 (2004): 848-855.

39. Kenneth A Egol., et al. "Early complication of proximal humerus fractures treated with locked plates". Orthopaedics and Traumatology 22 (2008): 159-164.

40. Herscovici D. "Case controversies. Proximal humerus fracture". Journal of Orthopaedic Trauma 15 (2001): 146-148.

41. Rizwan Shahid., et al. "Proximal humerus fracture treated with locking compression plate". Acta Orthopaedica Belgica 74 (2008): 602-608.

42. MA Fazal and FS Haddad. "PHILOS plate fixation for displaced proximal humeral fractures". Journal of Orthopaedic Surgery 17.1 (2009): 15-18.

Citation: Dhruv Pandya and Krunal Soni. "Analysis of Functional Outcome in Proximal Humerus Plating (PHILOS) in Displaced Proximal Humerus Fracture". Acta Scientific Orthopaedics 3.11 (2020): 37-49. 
43. Cofield RH. "Comminuted fractures of the proximal humerus". Clinical Orthopaedics 230 (1988): 49-57.

44. Cordasco FA and Bigliani LU. "Complications of proximal humerus fractures". Techniques in Orthopedics (1997): 12-50.

45. Frigg R. "Development of the locking compression plate". Injury 34 (2003): 6-10.

46. AA Martinez., et al. "Proximal humerus locking plate for proximal humerus fracture-retrospective study". Journal of Orthopaedic Surgery 17.1 (2009): 10-14.

47. Neer CS. "Displaced proximal humeral fracture: Part 1: Classification and evaluation". Journal of Bone and Joint Surgery 52-A (1970): 1077-1089.

48. Evan L Flatow. "Fracture of the proximal humerus". Chapter-25, In: Text book of Rockwood and Green's fractures in adults. Volume 1, New York: Lippincott Williams and Wilkins (2001): 997-1035.

49. Neviaser AS., et al. "Rate of avascular necrosis following proximal humerus fractures treated with a lateral locking plate and endosteal implant". Archives of Orthopaedic and Trauma Surgery 131.12 (2011): 1617-1622.

50. Kavuri V., et al. "Complications Associated with Locking Plate of Proximal Humerus Fractures". The Indian Journal of Orthopaedics 52.2 (2018): 108-116.

51. Dheenadhayalan J., et al. "Correlation of radiological parameters to functional outcome in complex proximal humerus fracture fixation: A study of 127 cases". Journal of Orthopaedic Surgery 27.2 (2019): 230949901984816.

\section{Assets from publication with us}

- Prompt Acknowledgement after receiving the article

- Thorough Double blinded peer review

- Rapid Publication

- Issue of Publication Certificate

- High visibility of your Published work

Website: https://www.actascientific.com/

Submit Article: https://www.actascientific.com/submission.php

Email us: editor@actascientific.com

Contact us: +919182824667

Citation: Dhruv Pandya and Krunal Soni. "Analysis of Functional Outcome in Proximal Humerus Plating (PHILOS) in Displaced Proximal Humerus Fracture". Acta Scientific Orthopaedics 3.11 (2020): 37-49. 